Auch Schwefel und dessen Verbindungen lassen sich auf diese Weise durch die eintretende Heparreaction erkennen.

\title{
Ueber die Verdichtung der Luft auf der Oberfläche des Platins
} hat J. Lawrence $\mathrm{Smith}$ ) einige Beobachtungen veröffentlicht.

Wägt man ein reines Platingefäss, reibt es dann gut mit einem Stück trockenen weichen Papiers ab und bringt es wieder auf die Wagschale, so zeigt sich, dass es an Gewicht abgenommen hat und zwar beträgt die Gewichtsabnahme bei einem Platintiegel von gewöhnlicher Grösse 2 Milligramme oder mehr. Lässt man das Gefäss 15-20 Minuten auf der Wage stehen, so hat es sein ursprüngliches Gewicht wiedererlangt. Diese Verschiedenheit des Gewichtes hat man gewöhnlich der Feuchtigkeit zugeschrieben; der Verfasser hat nun durch seine Versuche festgestellt, dass Feuchtigkeit nicht die Ursache davon ist.

Eine neue Platinschale mit flachem Boder, deren Durchmesser 4 and deren Höhe 2 Centimeter betrug und welche eine Gesammtoberfläche (Innen- und Aussenwandung) von etwa 50 Quadratcentimeter hatte, wurde zunächst durch Kochen mit Aetznatronlauge gründlich gereinigt, mit destillirtem Wasser völlig abgewaschen, zur Rothgluth erhitzt und nach einstündigem Stehen, zum Behufe der Abkühlung, gewogen. Dann wurde sie von der Wage genommen und mit reinem Filtrirpapier abgerieben ohne stark aufzudrücken und indem man Sorge trug, soweit thunlich keinen Theil der Oberfläche zu vergessen. Als nun die Schale wieder auf die Wage gebracht wurde, zeigte es sich, dass sie um 2 Milligramm an Gewicht abgenommen hatte; nach 20 Minuten Iangem Stehen hatte sie wieder ihr ursprüngliches Gewicht angenommen. Jetzt brachte man die Schale in einen Exsiccator über Schwefelsäure und liess sie 6 Stunden darin; nach Ablauf dieser Zeit war ihr Gewicht genau dasselbe wie vor dem Einbringen in den Exsiccator; nachdem man sie neuerdings mit Filtrirpapier abgericben, wie oben angegeben, zeigte sich wieder eine Gewichtsabnahme von 2 Milligramm, nach 15-20 Minuten kehrte die Schale zum ursprünglichen Gewicht zurück. Nunmehr wurde die Schale in ein geschlossenes Gefäss gebracht, in welchem durch Einlegen nassen Papieres die Luft mit Feuchtigkeit gesättigt war und 6 Stunden darin gelassen. Nach Ablauf dieser Zeit war das Gewicht ebenso wie vor dem Einbringen in die mit Feuchtigkeit gesättigte Luft.

*) Chem. News 31, 55.

Fresenius, Zeitschrift. XIV. Jahrgang. 
Es geht daraus hervor, dass das Verweilen in einer trockenen oder feuchten Atmosphäre ohne Einfluss anf das Gewicht eines Platingefässes ist, dass sich aber anf der Oberfläche des Platins stets eine Schicht verdichteter Luft befindet, welche durch Reiben entfernt werden kann.

Für den Chemiker folgt daraus die Regel, dass man Platingefässe nicht gleich nach dem Abreiben wägen darf, sondern erst einige Zeit nachher.

Eine tausendtheilige Thermometerscala bringt J. Williams*) in Vorschlag. Er empfiehlt als Nullpunkt der Scala den Gefrierpunkt des Quecksilbers, gleich $-40^{\circ} \mathrm{C}$, und als Endpunkt derselben den Siedepunkt des Quecksilbers, gleich $360^{\circ} \mathrm{C}$, zu nehmen und den Zwischenraum in 1000 Theile zu theilen. Der Gefrierpunkt des Wassers liegt dann bei $100^{\circ}$ and der Siedepunkt bei $360^{\circ} ; 15$ solcher Grade sind gleich $2^{0} \mathrm{C}$.

Ueber Hirn's Lufthermometer und dessen Anwendung zur Bestimmung der Feuchtigkeit der Dämpfe und der Temperatur der Heizgase hat 0 . Halla u e $\mathrm{r}^{* *}$ ) interessante Mittheilungen veröffentlicht, auf welche wir hier nur aufmerksam machen können.

Gasentwickelungsapparate haben C. J. Woodward***) und Hermann Kämmerer $\dagger$ ) construirt. Woodward gibt zwei Apparate an, von denen der eine für Gasentwicklungen in grösserem, der andere für solche in kleinerem Maassstabe bestimmt ist. Ersterer ist eine Modification des in dieser Zeitschrift 8, 139 beschriebenen und daselbst Taf. III Fig. 1 abgebildeten Seelhorst'schen Apparates; der Habn F und das Gefäss C (siehe die Fig. a. a. O.) fehlen, das Heben und Senken des Säurestandes wird durch Eintauchen oder Herausziehen eines Klotzes $G$ bewerkstelligt, welcher an einer. über zwei Rollen laufenden Schnur befestigt ist, wie dies ans Figur 16 (a. f. Seite) ohne weitere Erklärung ersichtlich ist. Der zweite für Entwickelungen in kleinerem Maassstabe bestimmte beruht auf gleichem Princip wie der in dieser Zeitschrift 11, 429 beschriebene und abgebildete Wartha'sche Apparat und unterscheidet sich auch in der Form nur unwesentlich von letzterem.

*) Chem. News 31, 214.

**) Bull. de la société industrielle de Mulhouse 1874 p.417 und Dingler's pol. Journ. 215, 511.

***) Chem. News 28, 209.

†) Ber. d. deutsch. chem Gesellsch. z. Berlin 7, 1724. 